Bulletin d'Histoire Contemporaine de I'Espagne

$54 \mid 2020$

Les espaces du politique dans l'Espagne du Trienio liberal (1820-1823)

\title{
La dinamización de la Transición política española a través del asesinato de los abogados de Atocha
} Manuel GALLEGO LÓPEZ

\section{CpenEdition}

\section{Journals}

Edición electrónica

URL: http://journals.openedition.org/bhce/3097

DOI: 10.4000/bhce.3097

ISSN: 1968-3723

\section{Editor}

Presses Universitaires de Provence

\section{Edición impresa}

Fecha de publicación: 1 enero 2020

ISSN: 0987-4135

\section{Referencia electrónica}

Manuel GALLEGO LÓPEZ, «La dinamización de la Transición política española a través del asesinato de los abogados de Atocha », Bulletin d'Histoire Contemporaine de l'Espagne [En línea], 54 | 2020,

Publicado el 01 julio 2020, consultado el 01 enero 2021. URL : http://journals.openedition.org/bhce/ 3097 ; DOI : https://doi.org/10.4000/bhce.3097

Este documento fue generado automáticamente el 1 enero 2021.

Bulletin d'histoire contemporaine de l'Espagne 


\title{
La dinamización de la Transición política española a través del asesinato de los abogados de Atocha
}

\author{
Manuel GALLEGO LÓPEZ
}

\section{NOTA DEL EDITOR}

Tesis defendida el 10 de febrero de 2016 en el Departamento de Historia Contemporánea de la Universidad Nacional de Educación a Distancia (UNED). Directora: Rosa María Martínez Segarra (UNED). Tribunal: Presidente. Juan Avilés Farré (UNED). Secretaria: Cristina Barreiro Gordillo (U. San Pablo-CEU). Vocal: José Babiano Mora (Director del Área de Historia, Archivos y Biblioteca. Fundación 1ํMayo).

Poco después de las diez de la noche tuve que dejar el barrio. Otra reunión me esperaba en Atocha. Había muchas cosas de que hablar. Exprimir las pocas posibilidades de las leyes, hechas a medida del cruel silencio de aquellos tiempos. De Vallecas a Atocha, un camino repetido una y mil veces. Casi lo tenía aprendido de memoria. Pero aquella noche no iba a ser igual a tantas otras [...].

[...] Nos sentamos. Estoy de espaldas a la puerta. Junto a Luis Javier. Llaman al timbre. Abro yo. Abre Luisja. Nos tropezamos. Abre Luis Javier. Noto muecas extrañas en las caras de Lola, Javier, Enrique. Algo raro sucede. La inminencia de algo imposible o absurdo, de alguna sorpresa, se nos echaba encima, como si todos los demonios nos hubieran cercado con sus terribles garras de acero. Me vuelvo de cara a la puerta. En segundos, pasamos de la relajación a la sorpresa total, a la tensión, al miedo. A la sangre, a la muerte. Nos hace ponernos de pie. Juntos en la esquina del vestíbulo. Un hombre seco, oscuro, de mirada fija, mentón pronunciado. Las manos en alto; bien arriba.

'Esas manitas bien arriba'-. Tiemblan nuestros huesos. Bien armado. Una enorme pistola que baila en la mano derecha. Otro, encapuchado, recorre los despachos. No entendemos nada. Querrán registrar el despacho. Quieren saber algo de Navarro; líder sindical de transporte: -Sí, ese de pecas, andaluz-. Javier interviene -No sabemos de quien habláis-. -Esas manos bien arriba-. Suena un disparo en la otra 
habitación. No nos lo creemos. Temblamos por dentro y por fuera. Nos sentimos unidos, inmensamente unidos.

-Dónde está ese Navarro. Es mejor para vosotros que nos lo digáis-. Estamos agrupados en la esquina del salón; juntos; las manos en alto; un infinito bosque de brazos y manos detenidas, entregadas, dispuestas, y una tensión sólida, cortante, gélida, de espera. Desde ese momento hasta que salimos del despacho, toda una eternidad queda detrás de nuestra sangre.

Se juntan los dos delante nuestro y comienzan a disparar avasalladoramente, brutalmente. Una tremenda sucesión de disparos nos va tirando al suelo y destrozando por dentro y por fuera. Estamos viviendo nuestra ejecución; los cuerpos de todos por los aires, en el suelo, contra los bancos; buscando protección. Nos estaba llegando la muerte; gritos sordos, acallándose.

Tiro a tiro, terminan con todo movimiento. En el suelo, nos rematan. Somos un enorme charco de sangre, un montón de cuerpos encogidos; un silencio de cal viva"1.

1 Con estas escalofriantes palabras describía Alejandro Ruiz-Huerta, sobreviviente de la masacre, el brutal atentado que sufrieron nueve abogados laboralistas en un despacho situado en la calle Atocha número 55, que se saldó con cinco muertos y cuatros heridos muy graves, el 24 de enero de 1977.

El ataque al bufete se realizó durante la transición, un periodo de incertidumbre e inestabilidad política en el que la sociedad española se encontraba dividida entre una mayoría que deseaba la implantación de una democracia, aunque con distintas posturas de cómo debería llevarse a cabo la reforma, y una minoría que ambicionaba la continuidad del franquismo.

3 El trabajo efectuado por el Partido Comunista de España (PCE) durante la dictadura convirtió al movimiento obrero en una de las principales preocupaciones del régimen, al que solo supo responder con represión. Su movilización no terminó con la muerte de Franco, pues era en democracia donde tenían que luchar por conseguir sus derechos y libertades, que hacía tan solo unos meses parecían inalcanzables. Para ello, con el apoyo de los sindicatos, tomaron las calles, convirtiendo 1976 en el año con más huelgas y manifestaciones de la historia de España.

4 Ante esta oleada social, el Gobierno no podía dar marcha atrás. El camino hacia un cambio pacífico pasaba por el establecimiento de una democracia amplia, que dejase de lado por completo el régimen anterior.

5 Mientras, los continuistas, tras la muerte del dictador, lucharon por construir un Gobierno de corte franquista o con los menos cambios posibles. Eran personas de muy distinto origen que, en su mayoría, habían tenido una gran influencia política y económica durante el régimen e, incluso, algunos habían ayudado a construirlo y estaban observando cómo desaparecía todo aquello por lo que habían luchado.

6 Sin embargo, los continuistas llegaron muy fragmentados al proceso de cambio ya que, tras la muerte de Carrero Blanco, sus personalidades más influyentes elaboraron distintos proyectos que tratarían de llevar a cabo mediante la victoria en las elecciones generales de 1977. Estos se agruparon, especialmente, en torno a dos figuras con gran influencia durante la dictadura: Manuel Fraga Iribarne, quien fundó Alianza Popular, y Blas Piñar López, que trató de unir todos los partidos tradicionalistas bajo las mismas siglas.

7 A pesar de los llamamientos a la unidad realizados por una parte de la extrema derecha, las organizaciones convirtieron sus diferencias ideológicas y estratégicas en cuestiones 
innegociables para la formación de una coalición, principalmente por las discrepancias personales y el ego de sus dirigentes. Además, su defensa incondicional del periodo franquista, en el caso de Blas Piñar, de los primeros años de la dictadura, les hizo perder numerosos apoyos.

Por su parte, la Iglesia y el Ejército, dos de los pilares que habían ayudado a salvaguardar el franquismo, estaban perdiendo su vieja influencia en el ámbito político y sobre el conjunto de la sociedad. En el caso de la institución eclesiástica, debido a las nuevas doctrinas provenientes del Concilio Vaticano II, mientras que, en el Ejército, la política de ascensos iniciada por Arias Navarro y continuada por Suárez favoreció las rupturas ideológicas que desde finales de los sesenta se estaban haciendo visibles en el seno de la institución.

9 A la inestabilidad política y social se unió la acción de grupos terroristas que intentaron alcanzar sus reivindicaciones por la fuerza de las armas. Al desafío terrorista el Estado respondió con un uso desmedido de la represión, lo que ocasionó una espiral de violencia que acabó con la vida de, aproximadamente, seiscientas personas entre los años 1975 y 1982.

10 El primer Gobierno de la Monarquía, compuesto por importantes personalidades del franquismo, algunas de las cuales habían dado muestras de un talante reformista, fue incapaz de hacer frente a la nueva coyuntura. Los sucesos de Montejurra y de Vitoria, el encarcelamiento de varios miembros de la Platajunta y el aumento de la conflictividad social y laboral fueron factores que, en un contexto de recesión económica, provocaron una crisis de credibilidad política en el Gobierno de Arias Navarro, pues su respuesta a estos problemas se consideró un intento de continuismo.

11 Ante esta situación, el 1 de julio de 1976, el rey, asesorado por Torcuato Fernández Miranda, pidió la dimisión de Arias Navarro, quien sería sustituido por Adolfo Suárez, que entendió que el único camino hacia una transición política pacífica pasaba por la instauración de un sistema democrático.

12 Con un panorama social tan desconcertante, diciembre de 1976 y enero de 1977 se convirtieron en meses clave para el proyecto de reforma política en favor de la democracia y en contra de los partidarios del continuismo. Sesenta días de cambio que estuvieron acompañados de un ascenso de violencia callejera sin precedentes, que provocaría una gran inestabilidad política y social y despertaría viejos horrores del pasado.

13 En diciembre de 1976, se produjo la detención y posterior liberación de Santiago Carrillo; Antonio María de Oriol y Urquijo, presidente del Consejo de Estado y consejero nacional permanente, era secuestrado por los Grupos de Resistencia Antifascista Primero de Octubre (GRAPO); cuatro días más tarde, los españoles aprobaron mediante referéndum la Ley para la Reforma Política, que ponía fin a las Leyes Fundamentales del franquismo; mientras que, en enero de 1977, el Gobierno suprimió el Tribunal de Orden Público (TOP), institución de carácter político que aplicaba Justicia durante la dictadura; además, trabajadores asesorados por dirigentes de Comisiones Obreras iniciaron una huelga en la rama de transporte del Sindicato Vertical, que tras la eliminación del TOP se había convertido en la última institución de origen franquista.

Tras estos sucesos, entre los días 23 y 29 de enero se desarrolló la Semana Negra de la transición. Con este nombre se denomina a la escalada de violencia que tuvo lugar en la 
ciudad de Madrid y que conmocionó a todo el país y puso al Gobierno de Suárez al borde del colapso político.

Siete días de enero que comenzaron con el asesinato de Arturo Ruiz por los disparos realizados por un joven ultraderechista, durante una manifestación en favor de la amnistía para los presos políticos. Al día siguiente los GRAPO secuestraban al teniente general Emilio Villaescusa Quilis, presidente del Consejo Supremo de Justicia Militar. Horas más tarde una joven estudiante, María Luz Nájera, era alcanzada por un bote de humo de la policía, causándole la muerte. Esa misma noche se produjo el ataque a un bufete de abogados laboralistas, por parte de un comando de ultraderecha, que se saldó con cinco muertos y cuatro heridos muy graves. Tres días después los GRAPO asesinaron a tres miembros de las fuerzas del orden en dos atentados.

No obstante, un panorama tan delicado no evitó que cientos de miles de personas tomaran las calles del centro de la capital para dar el último adiós a los letrados asesinados, sepelio que las instituciones calificaron como de alto riesgo, llegando a afirmar que no podrían garantizar la seguridad de los asistentes. Sin embargo, la jornada de luto se saldó sin incidentes y nos ha dejado para la memoria una de las imágenes más significativas de la transición española a la democracia.

En virtud de ello, analizamos la influencia que tuvieron el asesinato de los abogados laboralistas, la organización del entierro y la respuesta ciudadana en el proceso de cambio y, muy especialmente, en la legalización del Partido Comunista de España.

Tres meses después, agentes de la policía nacional detenían a los presuntos autores de la masacre, todos ellos relacionados con el sector del transporte, pero no sería hasta tres años más tarde cuando el juez dictase una sentencia. Antes de llegar al 18 de febrero de 1980, fecha en que se fijaría la vista oral y pública del juicio, el proceso pasó por una larga instrucción sumarial, en la que fueron constantes los enfrentamientos entre los abogados de la acusación particular y el juez instructor y durante la que se comprometió a diversas instituciones del Estado, como la Dirección General de Seguridad, la Audiencia Nacional, el Ejército e, incluso, el Ministerio de Gobernación.

Durante las siete sesiones que tuvo el juicio, la acusación particular trató de demostrar distintos aspectos que no habían podido ser suficientemente investigados durante la instrucción, mientras que los abogados de la defensa adujeron, de una manera arrogante, motivos patrióticos a la actuación de sus defendidos y, por lo tanto, solicitaron la amnistía para todos ellos.

A pesar de la presión que tuvo que soportar el magistrado, pues la sala de audiencias estuvo repleta de jóvenes ultraderechistas, vestidos con camisa azul e insignias falangistas, que tuvieron un comportamiento cada vez más agresivo y dominante, condenó a los procesados a más de novecientos años, poniendo fin a uno de los sucesos más importantes de la transición española. 


\section{NOTAS}

1. Alejandro Ruiz-Huerta Carbonell, La memoria incomoda: los abogados de Atocha, Burgos, Dossoles, 2002, p. 125-129. 